\title{
Thermospheric wind during a storm-time large-scale traveling ionospheric disturbance
}

\author{
K. Shiokawa, ${ }^{1}$ Y. Otsuka, ${ }^{1}$ T. Ogawa, ${ }^{1}$ S. Kawamura, ${ }^{2,4}$ M. Yamamoto, ${ }^{2}$ S. Fukao, ${ }^{2}$ \\ T. Nakamura, ${ }^{2}$ T. Tsuda, $^{2}$ N. Balan, ${ }^{3}$ K. Igarashi, ${ }^{4}$ G. Lu, ${ }^{5}$ A. Saito, ${ }^{6}$ and K. Yumoto ${ }^{7}$ \\ Received 24 April 2003; revised 11 July 2003; accepted 17 September 2003; published 4 December 2003.
}

[1] A prominent large-scale traveling ionospheric disturbance (LSTID) was observed in Japan during the major magnetic storm (Dst $\sim-358$ nT) of 31 March 2001. It was detected as enhancements of the 630-nm airglow and foF2, GPS-TEC variations, and a decrease in $F$-layer virtual height at 1700-1900 UT (0200-0400 LT). It moved equatorward with a speed of $\sim 600 \mathrm{~m} / \mathrm{s}$. The decrease in the $F$-layer height was also detected by the MU radar at Shigaraki. Thermospheric wind variations were observed by the MU radar through ion drift measurement and by a Fabry-Perot interferometer (FPI) through a Doppler shift of the 630-nm airglow line at Shigaraki. The wind data show a turn of the meridional wind from $-94 \mathrm{~m} / \mathrm{s}$ (equatorward) to $+44 \mathrm{~m} / \mathrm{s}$ (poleward) during the LSTID, indicating that an intense poleward wind in the thermosphere passed over Shigaraki as an atmospheric gravity wave and caused the observed ionospheric features of the LSTID. Intense poleward wind was also detected at mesospheric altitudes (95$100 \mathrm{~km}$ ) by the MU radar (through meteor echoes) and by the FPI (through the 558-nm airglow) with a delay of $\sim 2$ hours from the thermospheric wind, indicating downward phase progression of the wave. Generation of the observed poleward wind in the auroral zone was investigated using magnetic field data and auroral energy input estimated by the assimilative mapping of ionospheric electrodynamics (AMIE) technique. We suggest that simple atmospheric heating and/or the Lorentz force in the auroral zone do not explain the observed poleward wind enhancement. INDEX TERMS: 2435 Ionosphere: Ionospheric disturbances; 2437 Ionosphere: Ionospheric dynamics; 2443 Ionosphere: Midlatitude ionosphere; 2407 Ionosphere: Auroral ionosphere (2704); 0310 Atmospheric Composition and Structure: Airglow and aurora; KEYWORDS: large-scale traveling ionospheric disturbances, neutral wind, thermosphere dynamics, thermosphere-mesosphere coupling, magnetic storm, airglow imaging

Citation: Shiokawa, K., et al., Thermospheric wind during a storm-time large-scale traveling ionospheric disturbance, J. Geophys. Res., 108(A12), 1423, doi:10.1029/2003JA010001, 2003.

\section{Introduction}

[2] Large-scale traveling ionospheric disturbances (LSTIDs) are characteristic disturbances in the storm-time ionosphere at midlatitudes. They have a horizontal scale of more than $1000 \mathrm{~km}$ and propagate equatorward with a velocity of 400-1000 m/s [Hunsucker, 1982; Hocke and Schlegel, 1996]. These disturbances are probably caused by

\footnotetext{
${ }^{1}$ Solar-Terrestrial Environment Laboratory, Nagoya University, Toyokawa, Japan.

${ }^{2}$ Radio Science Center for Space and Atmosphere, Kyoto University, Uji, Japan.

${ }^{3}$ Department of Automatic Control and Systems Engineering, University of Sheffield, Sheffield, UK.

${ }^{4}$ Communications Research Laboratory, Koganei, Tokyo, Japan.

${ }^{5}$ High Altitude Observatory, National Center for Atmospheric Research, Boulder, Colorado, USA.

${ }^{6}$ Graduate School of Science, Kyoto University, Kyoto, Japan.

${ }^{7}$ Space Environment Research Center, Kyushu University, Fukuoka, Japan.

Copyright 2003 by the American Geophysical Union. 0148-0227/03/2003JA010001\$09.00
}

thermospheric waves generated by the auroral-zone energy input [e.g., Hooke, 1968; Francis, 1975; Reddy et al., 1990; Rice et al., 1988; Pi et al., 2000; Oyama et al., 2001]. Ho et al. [1996, 1998] obtained a two-dimensional image of the LSTIDs as global total electron content (TEC) maps using the multipoint GPS network.

[3] Model calculations of LSTIDs also show equatorward propagation of thermospheric waves from the auroral-zone energy input [e.g., Richmond, 1978; Millward et al., 1993; Fuller-Rowell et al., 1994; Fujiwara et al., 1996; Balthazor and Moffett, 1999]. Richmond [1978] predicted that the waves propagating equatorward at higher altitudes of the thermosphere precede those at lower altitudes. However, there have been few observations of the vertical structure of LSTIDs. Emery et al. [1996, 1999], Buonsanto et al. [1997], and $L u$ et al. [2001] combined empirical models of auroral energy input [e.g., Kamide et al., 1981; Richmond and Kamide, 1988] with the thermosphere-ionosphere electrodynamics general circulation model (TIEGCM) to describe storm-time thermospheric disturbances and LSTID generation. Most of these calculations show dominant enhancement of "equatorward wind" and associated upward motion 


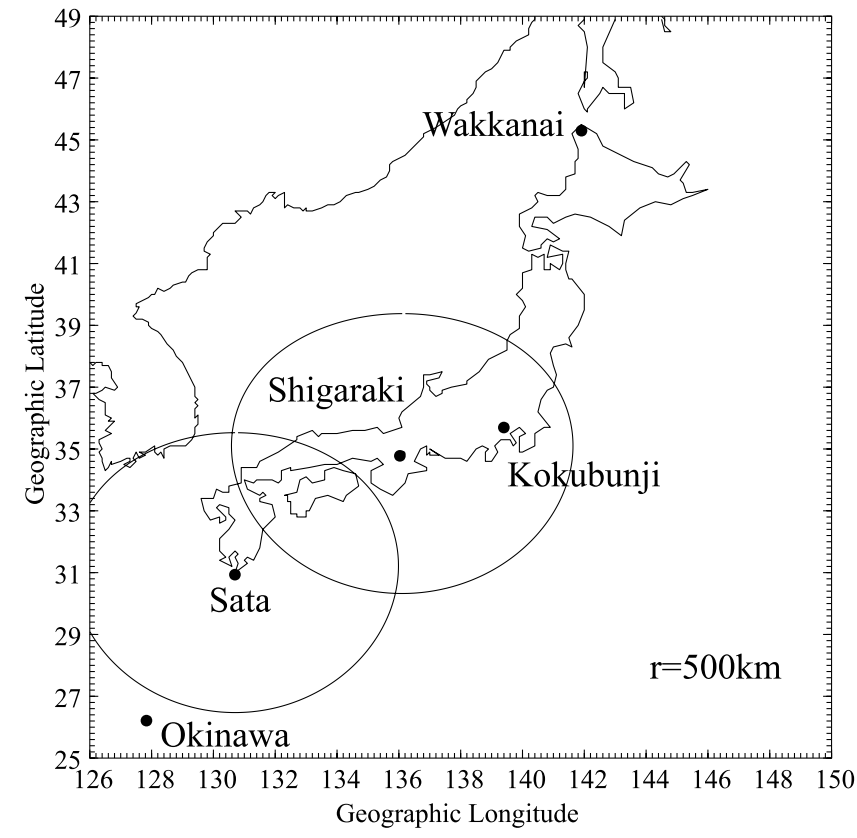

Figure 1. Map showing the locations of stations. The airglow data shown in Figures 3 and 4 were obtained at Shigaraki (magnetic latitude $\left(\right.$ MLAT) $=25.4^{\circ}$ ) and Sata $\left(21.2^{\circ}\right.$ MLAT), where the fields of view of the airglow imaging (radius of $500 \mathrm{~km}$ ) are shown. The ionogram data shown in Figure 7 were obtained at Wakkanai $\left(36.5^{\circ}\right.$ MLAT), Kokubunji $\left(26.5^{\circ} \mathrm{MLAT}\right)$, and Okinawa $\left(16.3^{\circ}\right.$ MLAT).

of the ionosphere in the midlatitudes during LSTID passage. The rise of the $F$ layer has been confirmed by observations [e.g., Ogawa and Kumagai, 1985; Tanaka, 1987; Hajkowicz and Hunsucker, 1987; Hajkowicz, 1990; Lee et al., 2002].

[4] Recently, Shiokawa et al. [2002] investigated a stormtime LSTID event of 15 September 1999, using airglow images, two-dimensional GPS-TEC maps, multipoint ionosondes, a midlatitude ionospheric model, and an empirical model of auroral energy input. They concluded that the drastic increases in airglow, TEC, and ionospheric peak density, and the decrease in ionospheric height, can be explained by the passage of "poleward" wind enhancement $(250-300 \mathrm{~m} / \mathrm{s})$ associated with the LSTID. However, direct measurements of thermospheric wind were not available for the previous observations of LSTIDs.

[5] In this paper, we report a prominent LSTID event observed in Japan during the magnetic storm of 31 March 2001. Enhancements of airglow, TEC, and ionospheric peak density, and a decrease in ionospheric height, which were similar to those reported by Shiokawa et al. [2002], were observed. Moreover, drastic enhancement of poleward wind was measured by the Middle and Upper Atmosphere (MU) radar and a two-channel Fabry-Perot interferometer (FPI) for two altitude ranges in the thermosphere and in the mesopause region, associated with the special MU radar operation for the Mesosphere-Thermosphere Experiments for Coupling Studies (MTEC-S) campaign for 23 March to 2 April 2001. The full description of the campaign is given by N. Balan (Simultaneous MLT and thermospheric $F$ region observations during geomagnetic storms, submitted to Journal of Geophysical Research, 2003). Temporal variations of wind indicate a delay in the LSTID propagation at lower altitudes. To discuss the generation of the observed LSTIDs, we compare these midlatitude data with high-latitude data from ground magnetometers and from the assimilative mapping of ionospheric electrodynamics (AMIE) technique.

\section{Observations}

[6] Figure 1 shows the locations of the ground-based stations used in this paper. The airglow enhancement was observed at Shigaraki $\left(34.8^{\circ} \mathrm{N}, 136.1^{\circ} \mathrm{E}\right.$, geomagnetic latitude $($ MLAT $\left.)=25.4^{\circ} \mathrm{N}\right)$ and Sata $\left(31.0^{\circ} \mathrm{N}, 130.7^{\circ} \mathrm{E}, 21.2^{\circ}\right.$ MLAT). The MU radar and a Fabry-Perot interferometer were also located at Shigaraki. Ionosonde measurements were made at Wakkanai $\left(45.4^{\circ} \mathrm{N}, 141.7^{\circ} \mathrm{E}, 36.5^{\circ} \mathrm{MLAT}\right)$, Kokubunji $\left(35.7^{\circ} \mathrm{N}, 139.5^{\circ} \mathrm{E}, 26.5^{\circ} \mathrm{MLAT}\right)$, and Okinawa $\left(26.3^{\circ} \mathrm{N}, 127.8^{\circ} \mathrm{E}, 16.3^{\circ} \mathrm{MLAT}\right)$.

[7] Figure 2 shows Dst indices (provisional) during the magnetic storm of 30 March to 1 April 2001. The minimum Dst was $-358 \mathrm{nT}$ at $0900 \mathrm{UT}$ on 31 March. The LSTID event (as shown by the vertical dashed line) to be reported here was observed during the main phase of the storm.

\subsection{Midlatitude Airglow}

[8] Three all-sky airglow imagers were used in this study. They were developed in the Solar-Terrestrial Environment Laboratory, Nagoya University, as part of the Optical Mesosphere Thermosphere Imagers (OMTIs) [Shiokawa et al., 1999, 2000]. Imagers 1 and 4 were set at Shigaraki, and imager 2 was set at Sata. They obtained airglow images at wavelengths of $630 \mathrm{~nm}$ (emission altitude: 200-300 km), $558 \mathrm{~nm}(90-100 \mathrm{~km})$, and $777 \mathrm{~nm}(300-400 \mathrm{~km})$ with time resolutions of $5.5-6.5 \mathrm{~min}$.

[9] Figures $3 b-3 e$ show north-south cross sections (keograms) of airglow images at these airglow lines on 31 March 2001, at Shigaraki (Figures 3b and 3d) and Sata

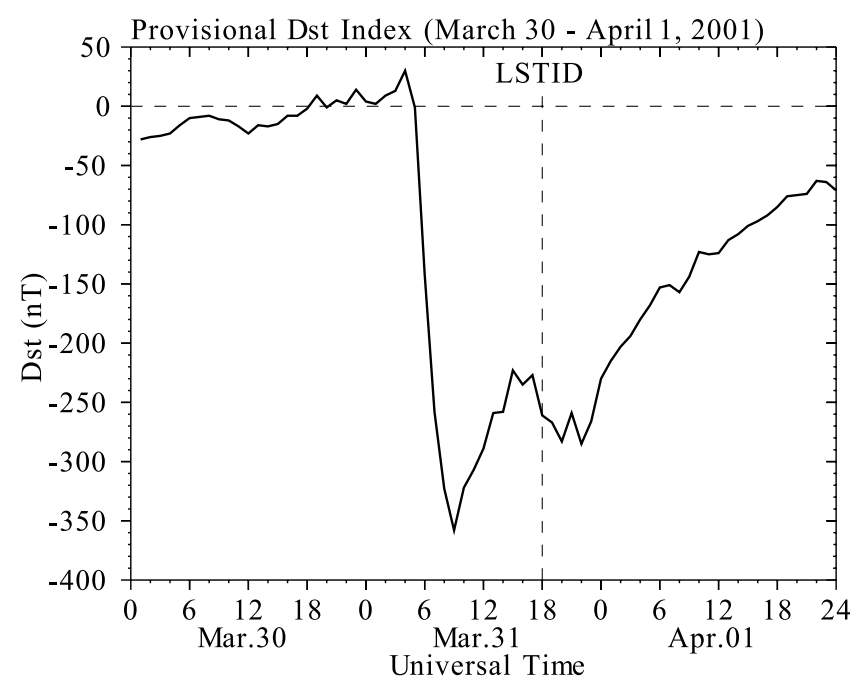

Figure 2. Three-day provisional Dst indices during the magnetic storm of 30 March to 1 April 2001. The vertical dashed line indicates the time when the large-scale traveling ionospheric disturbance (LSTID) was observed in Japan. 

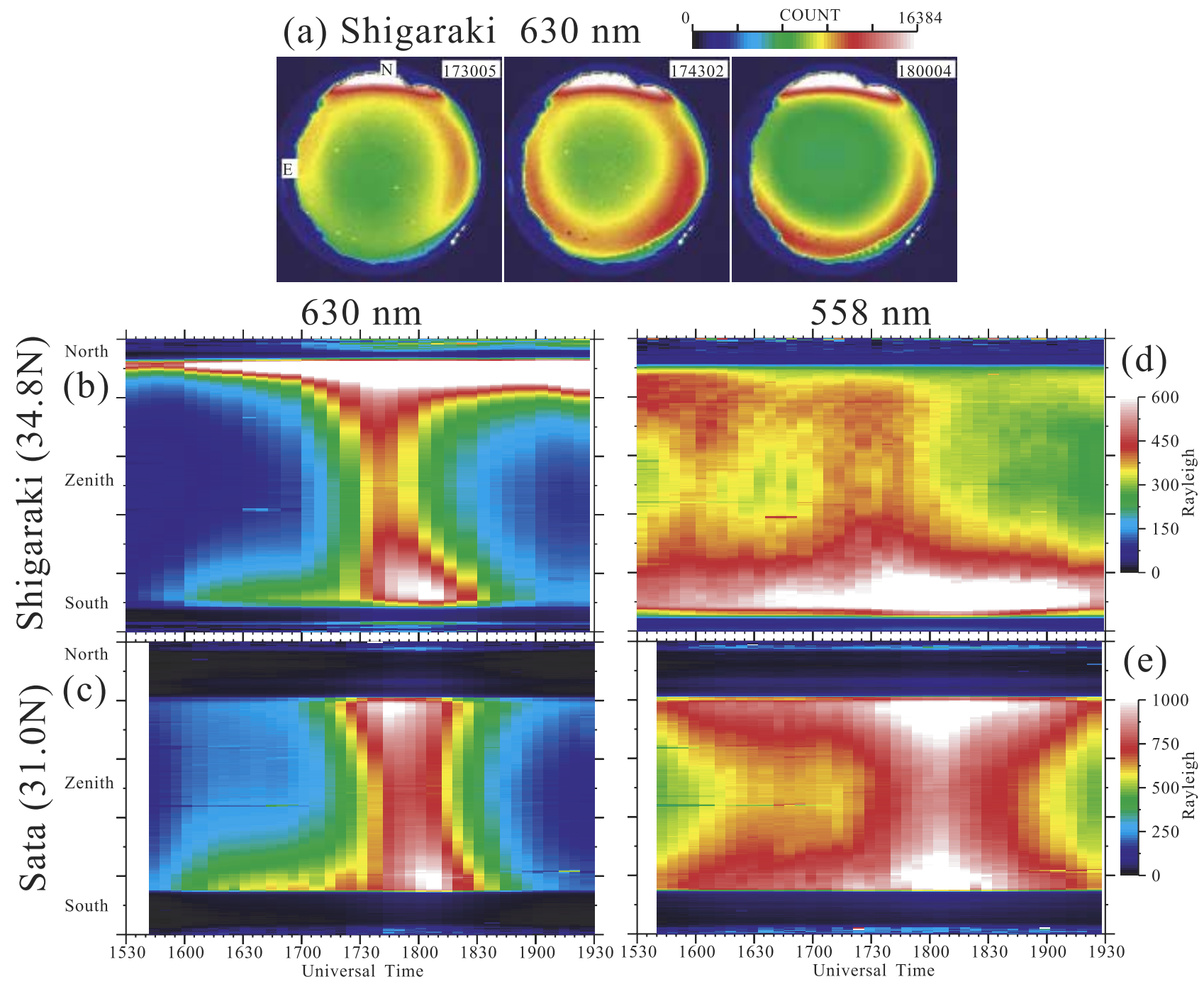

Figure 3. (a) All-sky airglow images at $630 \mathrm{~nm}$ and north-south cross sections (keograms) of all-sky images for airglow emissions at (b) $630 \mathrm{~nm}$ at Shigaraki, (c) $630 \mathrm{~nm}$ at Sata, (d) $558 \mathrm{~nm}$ at Shigaraki, and (e) $558 \mathrm{~nm}$ at Sata. The Van Rhijn effect (effect of oblique line-of-sight integration of airglow layer) is not corrected in the plotted data. These data were obtained by three all-sky imagers (imagers 1 and 4 at Shigaraki and imager 2 at Sata) on 31 March 2001. The LSTID passed over Shigaraki and Sata from north to south at 1700-1830 UT (0200-0330 LT).

(Figures 3c and 3e). The 630-nm images at Shigaraki are shown in Figure 3a. The intense 630-nm emission around the northern horizon of Shigaraki (Figures $3 \mathrm{a}$ and $3 \mathrm{~b}$ ) was probably from a stable auroral red (SAR) arc associated with low-energy electron precipitation from the inner magnetosphere. The SAR arc was also detected by an all-sky imager and photometers at Rikubetsu $\left(43.5^{\circ} \mathrm{N}, 143.8^{\circ} \mathrm{E}\right.$, Hokkaido, Japan, near Wakkanai in Figure 1), though the sky at Rikubetsu was mostly cloudy. The 630-nm emission was drastically enhanced at 1700-1830 UT (02000330 LT) at Shigaraki and Sata, as shown in Figures $3 \mathrm{~b}$ and $3 \mathrm{c}$. The enhancement propagated southward at both stations. The southward propagation can be seen in the allsky images in Figure 3a, though the emission around the edge of the images was high due to the line-of-sight integration (van Rhijn effect). The enhancement was also seen in the 558-nm emission, particularly at Sata (Figures 3d and $3 \mathrm{e}$ ). The 558-nm emission was unusually intense in the southern part of Japan (south of Shigaraki and around Sata) throughout the night.

[10] Figure 4 shows zenith airglow intensities extracted from Figure 3. The 630-nm enhancement was larger at Sata $(\sim 550 \mathrm{R})$ than at Shigaraki $(\sim 300 \mathrm{R})$. It is noteworthy that the 777-nm airglow slightly decreased at Shigaraki at this time. The 558-nm airglow intensity was unusually intense (more than 500 R) even before the LSTID passage over Sata. From the time difference of the $630-\mathrm{nm}$ airglow peak between Shigaraki and Sata, we estimate the southward component of LSTID velocity to be $\sim 640 \mathrm{~m} / \mathrm{s}$.

\subsection{Total Electron Content (TEC)}

[11] To show large-scale features of the LSTID, we made maps of TEC variations (Figure 5) during the $630-\mathrm{nm}$ airglow enhancement of 31 March 2001. The GPS-TEC measurements were conducted by the Geographical Survey 


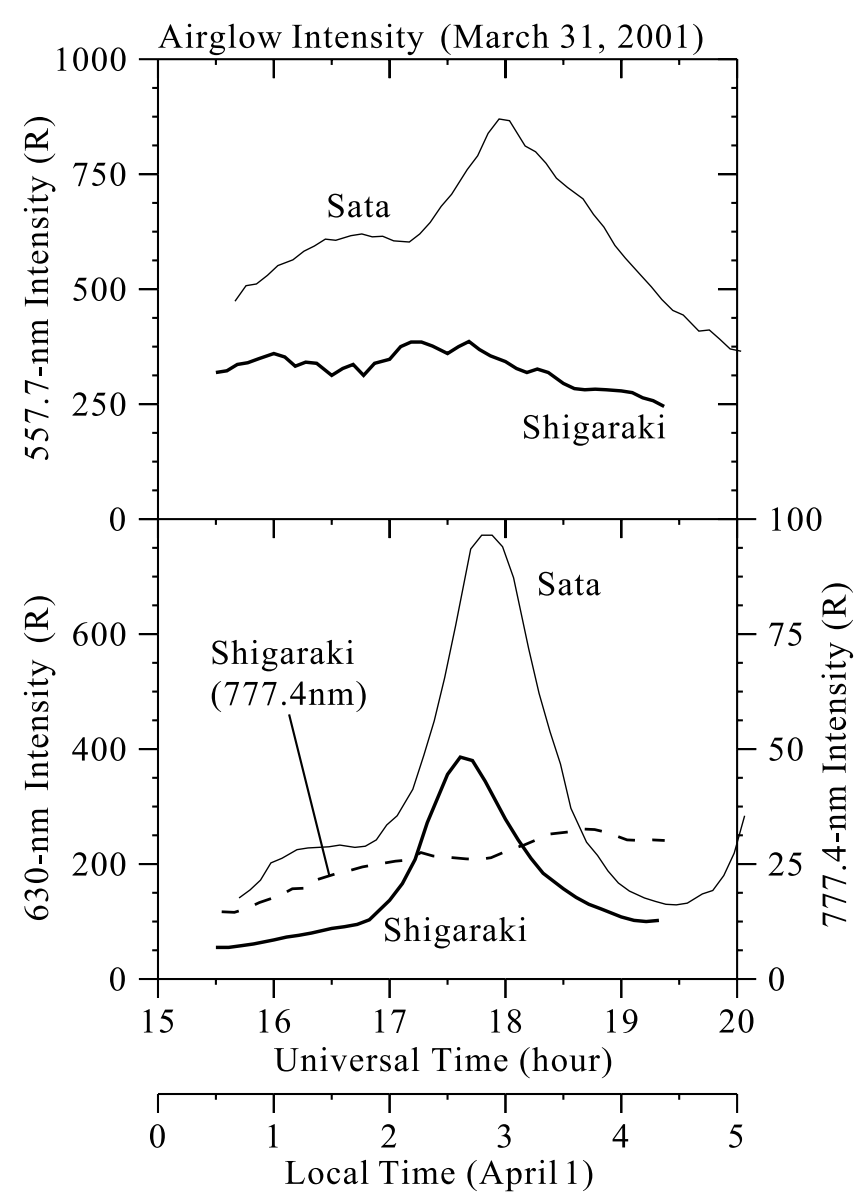

Figure 4. Variations in 630-nm, 777-nm, and 558-nm airglow intensities at zenith obtained by all-sky airglow imagers at Shigaraki and Sata on 31 March 2001.

Institute of Japan, using more than 1000 GPS receivers over Japan (GEONET) [Saito et al., 1998] with a time resolution of $30 \mathrm{~s}$. A running average of TEC over 1 hour was subtracted from the raw TEC values in order to avoid instrumental biases [Saito et al., 1998]. The TEC variations estimated along the line-of-sight between the GPS satellites and the ground receivers are plotted at the location at an altitude of $300 \mathrm{~km}$ in Figure 5. The 30-s resolution maps are shown every 5 min in Figure 5.

[12] In all the TEC maps, a continuous high-TEC region can be seen at the northern edge of Japan at $\sim 44^{\circ} \mathrm{N}$. Apart from this, an enhanced region of TEC gradually appeared around $38^{\circ} \mathrm{N}$ at $1705-1710$ UT. It was significantly enhanced around 1720 UT $\left(\sim 1\right.$ TECU $\left.=1 \times 10^{16} \mathrm{~m}^{-2}\right)$ and moved equatorward continuously with a velocity of $\sim 370-560 \mathrm{~m} / \mathrm{s}\left(=2-3^{\circ}\right.$ latitude $\left./ 10 \mathrm{~min}\right)$. The latitudinal scale size of the TEC enhancement was $\sim 600-800 \mathrm{~km}$, and the peak of the enhancement was $\sim 1-2$ TECU.

[13] As stated above, the TEC map shown in Figure 5 was obtained by subtracting 1-hour running averages of TEC variation from the raw TEC data in order to avoid instrumental biases. The instrumental biases vary significantly depending on the GPS receivers. The absolute TEC and TEC perturbations obtained at the location of Shigaraki are shown in Figures $6 a$ and $6 b$, respectively. The TEC variations in Figure $6 \mathrm{~b}$ are the same as those plotted in Figure 5. The absolute TEC in Figure 6a was estimated by correcting the instrumental bias for each receiver using TEC data from several GPS satellites at different elevation angles [Otsuka et al., 2002].

[14] The TEC variations in Figure $6 \mathrm{~b}$ show an enhancement of TEC with an amplitude of $\sim 2$ TECU at around 1725 UT associated with the LSTID passage. The absolute TEC in Figure 6a shows a slight increase at 1700-1720 UT and a significant decrease from 32 TECU to 25 TECU at 1720-1800 UT. Thus the actual TEC variations associated with the LSTID were not only the enhancement but also a subsequent significant decrease. The TEC enhancement of $\sim 2$ TECU is $\sim 6 \%$ of the background (absolute) TEC value ( $\sim 32$ TECU) at Shigaraki. From the latitudinal profile of the absolute TEC values (not shown), the TEC enhancement of $1-2$ TECU over Japan (Figure 5) was $\sim 2-6 \%$ from the background TEC values.

\subsection{Multipoint Ionosonde Observations}

[15] The ionospheric features during the LSTID were investigated using ionograms (every $15 \mathrm{~min}$ ) obtained with the three routine ionosondes, whose locations are shown in Figure 1. Figure 7 shows virtual heights at $2 \mathrm{MHz}$ and $f_{o F} 2$ obtained at Wakkanai, Kokubunji, and Okinawa during the LSTID event of 31 March 2001. The virtual height at $2 \mathrm{MHz}$ and $f o F 2$ correspond to the representative height of the nighttime bottomside $F$ layer and the square root of the peak electron density of the $F$ layer, respectively.

[16] The virtual height gradually increased and $f_{o F}$ gradually decreased for 0900-1400 UT (1800-2300 LT), which was expected from the recombination of $F$-region density after sunset. Then, the virtual height started to decrease after 1500-1600 UT (0000-0100) LT at all three stations. Note that the minimum of the virtual height at 1700-1900 UT came earlier at higher latitudes. After the minimum, the virtual height suddenly increased to more than $350 \mathrm{~km}$ at all stations. Just before the virtual height minimum, foF 2 showed a local peak at each station, which also came from higher latitudes to lower latitudes between 1600 and 1800 UT. The time of the virtual height minimum corresponds to the time when the drastic enhancement of 630-nm airglow was observed. During these drastic variations of the ionosphere after midnight, spread- $F$ signatures were observed at Wakkanai. From the time difference between the virtual height minimum at Wakkanai (1715 UT) and Okinawa (1815 UT), the equatorward velocity of the LSTID is estimated to be $580 \mathrm{~m} / \mathrm{s}$.

\subsection{F-Region Density Profile Obtained by the MU Radar}

[17] A more detailed view of the ionospheric $F$-layer was obtained from the incoherent scattering measurement using the MU radar. Figure 8 shows contours of the electron density profile with a time resolution of $15 \mathrm{~min}$ observed by the MU radar at Shigaraki on 31 March 2001. At this time, the MU radar measurement had a 1.5 hour cycle, with 1 hour for $F$-layer electron density and 0.5 hour for mesospheric meteor echoes. In Figure 8, the no-observation interval of 0.5 hour is linearly interpolated. 

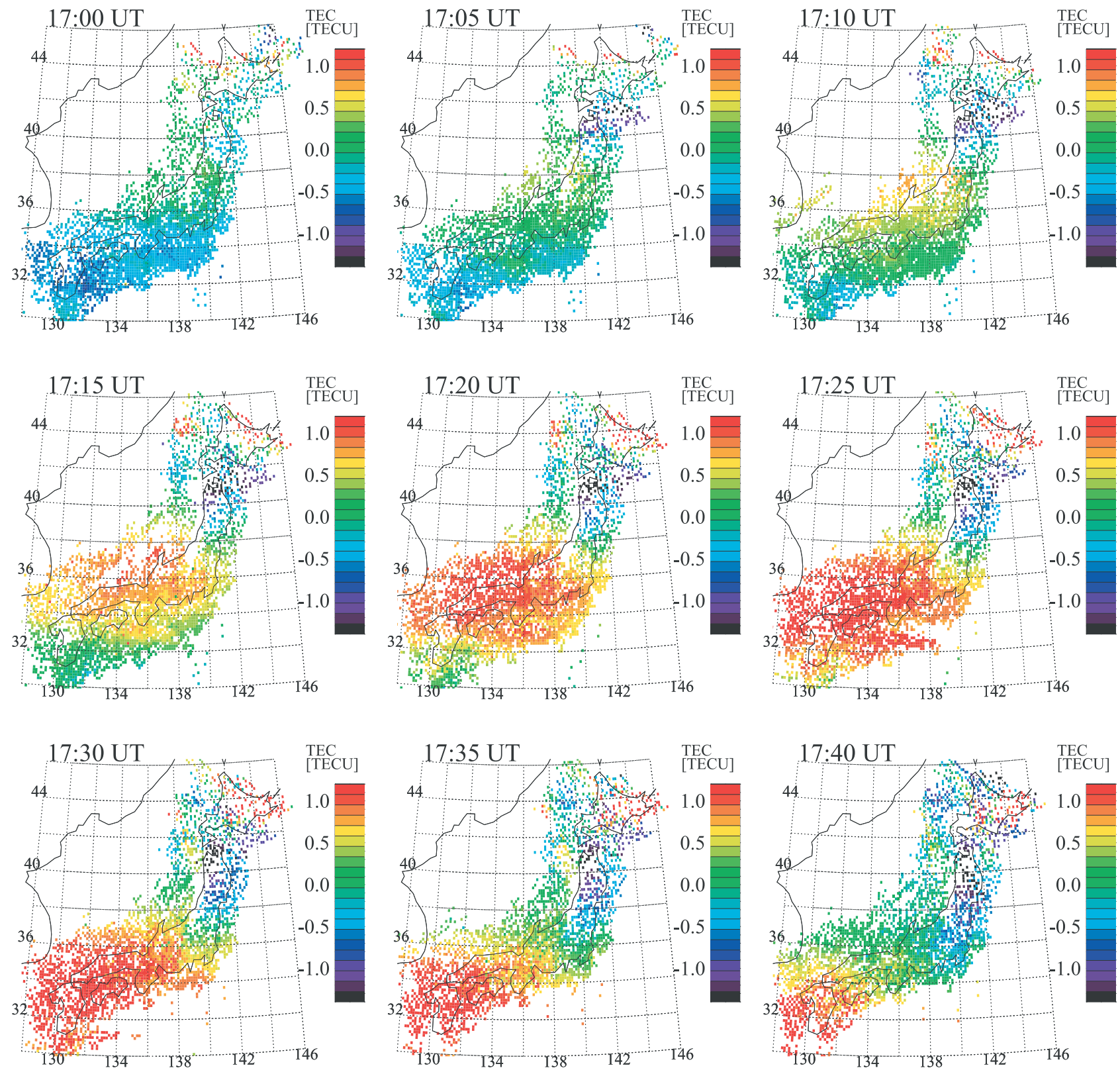

Figure 5. Two-dimensional maps of the total electron content (TEC) variations obtained by more than 1000 GPS receivers (GEONET) in Japan during the passage of the large-scale traveling ionospheric disturbance (LSTID) of 31 March 2001. A running average of TEC over 1 hour was subtracted from the raw TEC values, in order to avoid instrumental biases. The TEC values were mapped at an altitude of $300 \mathrm{~km}$ along the line-of-sight between the satellite and the ground receivers.

[18] The $F$-layer height around sunset was $400-450 \mathrm{~km}$, which is rather high compared with the normal $F$-layer peak height during magnetically quiet intervals [e.g., Kawamura et al., 2000]. The $F$-layer electron density gradually decreased and the peak height gradually increased after sunset from 1000 UT to $1300 \mathrm{UT}$, probably because of the recombination loss of $F$-layer electrons. Between $1300-$ $1530 \mathrm{UT}$, the velocity of the height increase becomes greater. At $1530 \mathrm{UT}$, the $F$ layer started to descend to the local minimum at $1745 \mathrm{UT}$, when the 630-nm airglow enhancement was observed. The peak density temporally increased at around 1645 UT. After 1745 UT, the $F$ layer almost disappeared, causing a sudden increase in peak height. These variations of electron density in Figure 8 are consistent with the variations of virtual height and $f_{0} F 2$ shown in Figure 7.

\section{Wind Measurements}

[19] For the LSTID event of 31 March 2001, several neutral wind data in the upper atmosphere were available. They were obtained by the MU radar and by a two-channel FPI. Both instruments are located at Shigaraki. The MU radar measured electron density and ion drift velocity in the $F$ layer, and neutral wind velocities in the mesosphere, alternatively, with a cycle time of 1.5 hours during the 


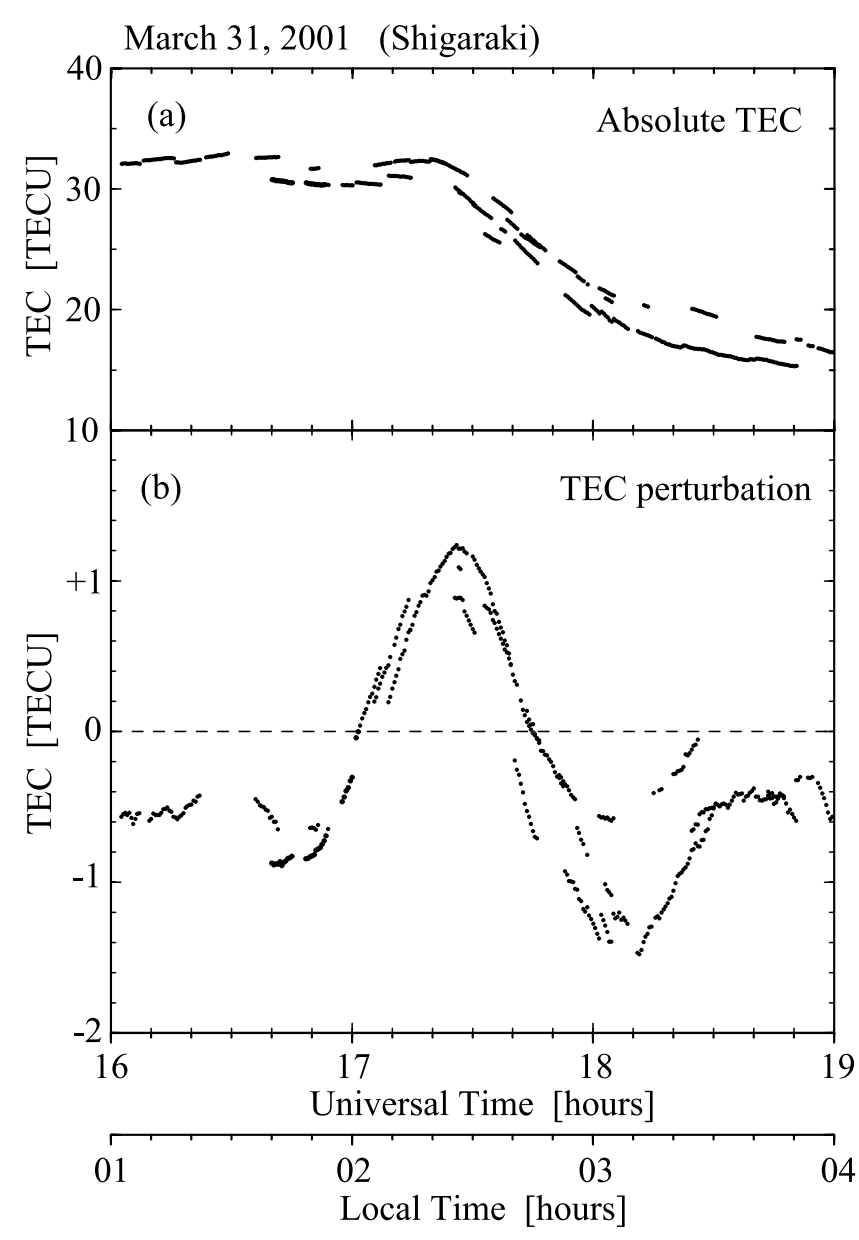

Figure 6. (a) Absolute total electron content (TEC) and (b) perturbations of TEC obtained by the GPS receivers of GEONET above Shigaraki $\left(34.8^{\circ} \mathrm{N}, 136.1^{\circ} \mathrm{E}\right)$, Japan on 31 March $2001\left(1 \mathrm{TECU}=1 \times 10^{16} \mathrm{~m}^{-2}\right)$. The absolute TEC was estimated by correcting instrumental biases using the method of Otsuka et al. [2002]. The TEC perturbations were obtained by subtracting 1-hour running average from the raw TEC data (same as those in Figure 5). The multiple values per each time correspond to different GPS satellites.

MTEC-S campaign for 23 March to 2 April 2001. The observation intervals were 1 hour and 0.5 hour for the $F$ layer and mesospheric wind measurements, respectively. The procedure for deriving $F$-layer neutral wind velocity from the ion drift measurement is described by Oliver et al. [1998]. The mesospheric wind measurement obtained through meteor echoes is described by Nakamura et al. [1991]. The two-channel azimuth-scan FPI measured wind velocities in the thermosphere and the mesopause region simultaneously with a time resolution of 1 hour through the Doppler shift of the 630-nm and 558-nm airglow lines [Shiokawa et al., 2003]. The emission altitudes of these airglow lines are $200-300 \mathrm{~km}(630 \mathrm{~nm})$ and $90-100 \mathrm{~km}$ $(558 \mathrm{~nm})$.

\subsection{Thermospheric Winds}

[20] Figure 9 shows northward wind velocities estimated from the $F$-layer ion drift measurement by the MU radar (thin and thick solid curves) and those measured by the FPI through the 630-nm airglow (thick dashed curve). The original time resolution of the MU radar data was 1.5 hours, while we took a running average of 4.5 hours ( 3 data points) throughout the observation interval to reduce statistical noise. The time resolution of the FPI was 1 hour. Because the moon was in the sky before midnight, the FPI measurement was started only after midnight.

[21] In Figure 9, the wind variations on 31 March were different from those seen on other days of the MTEC-S campaign. The average wind variation for 23 March to 1 April (thin solid curve with vertical bars indicating standard deviations) shows a typical tidal variation (southward wind around midnight), though there was another magnetic storm on 28 March (minimum $D s t \sim-100 \mathrm{nT}$ ). During the storm of 31 March, the MU wind (thick solid curve, 4.5-hour running average) shows large-amplitude wavelike variations, i.e., northward at 1200-1300 UT, highly southward at 14-16 UT, and northward at 1900-2100 UT. Considering that the northward (southward) wind pushes the $F$-layer upward (downward), these variations of meridional wind are fairly consistent with the observed height variations of the $F$ layer in Figure 8 (a rapid rise of the $F$ layer at 1300 1530 UT and a descent at 1530-1800 UT).

[22] During the LSTID event of 1700-1900 UT, the MU wind shows a turn from southward to northward at 16001900 UT. The FPI wind (thick dashed curve) shows a steeper increase in the northward (poleward) wind for 1546-1746 UT (from $-94 \mathrm{~m} / \mathrm{s}$ to $+44 \mathrm{~m} / \mathrm{s}$ ) with a higher time resolution of 1 hour. This sudden increase in poleward wind is consistent with the generation of LSTID signatures seen in the airglow, TEC, and height and peak density of the $F$ layer, as discussed in section 5.1.

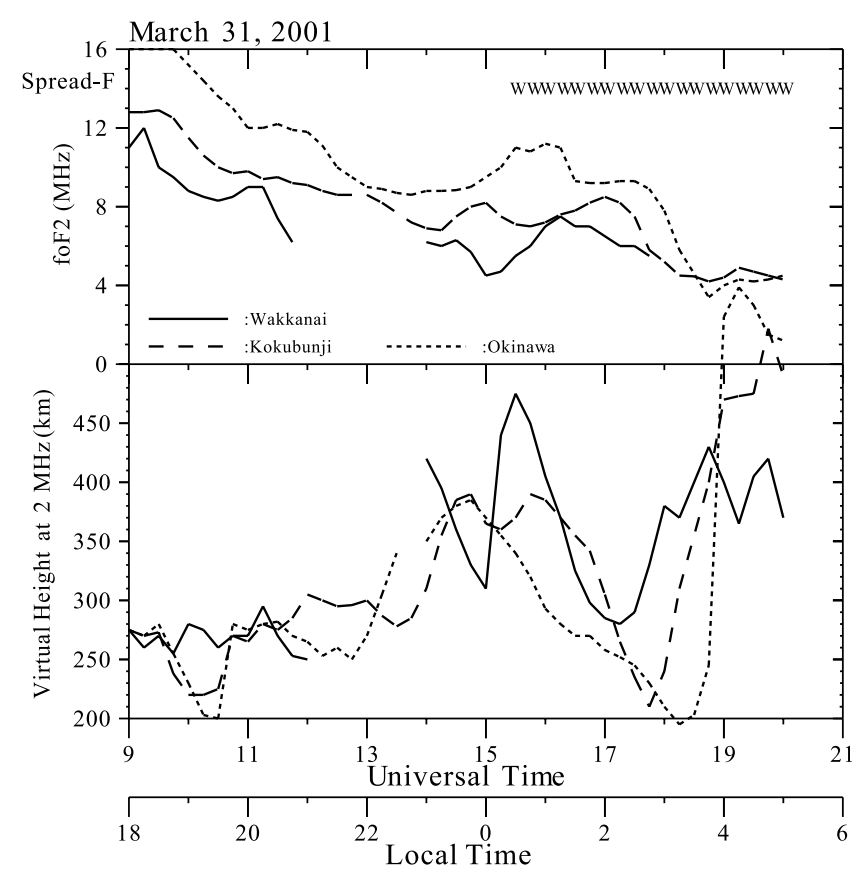

Figure 7. Variations in the $F$-region virtual height at $2 \mathrm{MHz}$ and $f_{o} F 2$ values obtained at three ionosonde stations in Japan during the large-scale traveling ionospheric disturbance (LSTID) of 31 March 2001. The station locations are shown in Figure 1. 


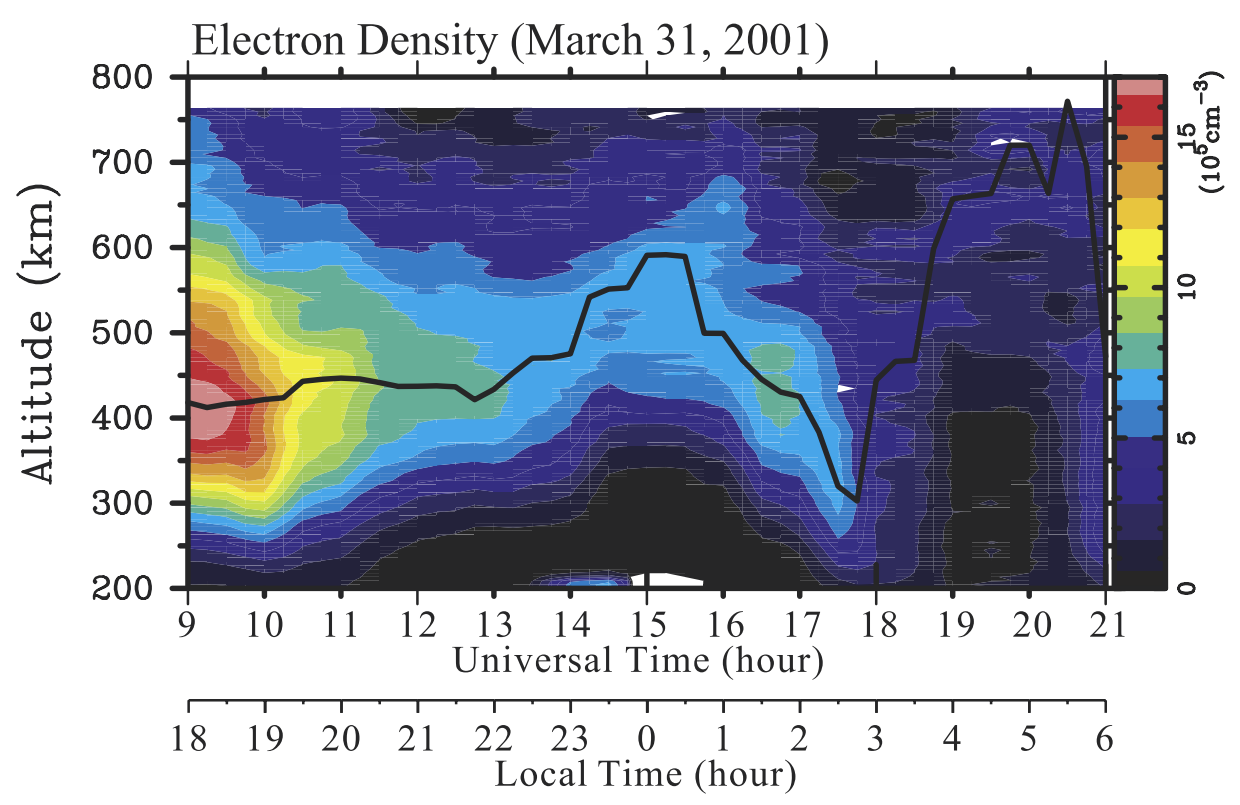

Figure 8. Nighttime electron density profile (15-min resolution) in the ionospheric $F$ layer measured by the MU radar at Shigaraki, Japan, during the magnetic storm of 31 March 2001. The solid curve indicates the peak heights of the electron density. The MU radar measurement was a 1.5 hour cycle, with 1 hour for the density profile and 0.5 hour for mesospheric meteor echoes. In this figure, the no-observation interval of 0.5 hour was linearly interpolated.

[23] The zonal wind measured by the FPI (not shown) on 31 March was generally $\sim 40 \mathrm{~m} / \mathrm{s}$ westward after midnight, with an enhancement of about another $30 \mathrm{~m} / \mathrm{s}$ westward only at 1746 UT. The zonal ion drift measured by the MU radar also shows an enhancement of the westward drift velocity at this time. The prevailing westward neutral wind was explained as the ionospheric disturbance dynamo described by Blanc and Richmond [1980]. Average stormtime neutral winds were recently reported by Fejer et al. [2002] on the basis of the FPI measurements made at Millstone Hill $\left(42.6^{\circ} \mathrm{N}, 288.5^{\circ} \mathrm{E}, 54^{\circ} \mathrm{MLAT}\right)$.

\subsection{Mesospheric Winds}

[24] Figure 10 shows the meridional wind profiles in the mesosphere obtained by the MU radar at Shigaraki through the meteor echoes on 30 March to 1 April 2001. The time resolution of the MU radar data was 1.5 hours (a 0.5 hour measurement every 1.5 hours). Diurnal tide variations with a downward phase progression were seen in this plot. Embedded in this diurnal variation was an unusually strong northward wind, observed at altitudes higher than $95 \mathrm{~km}$ (shown by the black arrow) at 1945 UT on 31 March which is just after the LSTID passage of 1700-1900 UT. The wind velocity increases with increasing altitude, and it exceeds $80 \mathrm{~m} / \mathrm{s}$ at altitudes above $98 \mathrm{~km}$.

[25] Figure 11 shows northward wind velocities measured by the MU radar at an altitude of $96 \mathrm{~km}$ and those measured by the FPI through the 558-nm airglow, in the same format as that in Figure 9. Just after the LSTID passage of 17001900 UT, the MU wind (thick solid curve) drastically increased up to $74 \mathrm{~m} / \mathrm{s}$ (poleward) at $1945 \mathrm{UT}$. This increase in wind was also seen in the FPI data, though the FPI measurement stopped after 1900 UT because of sunrise.

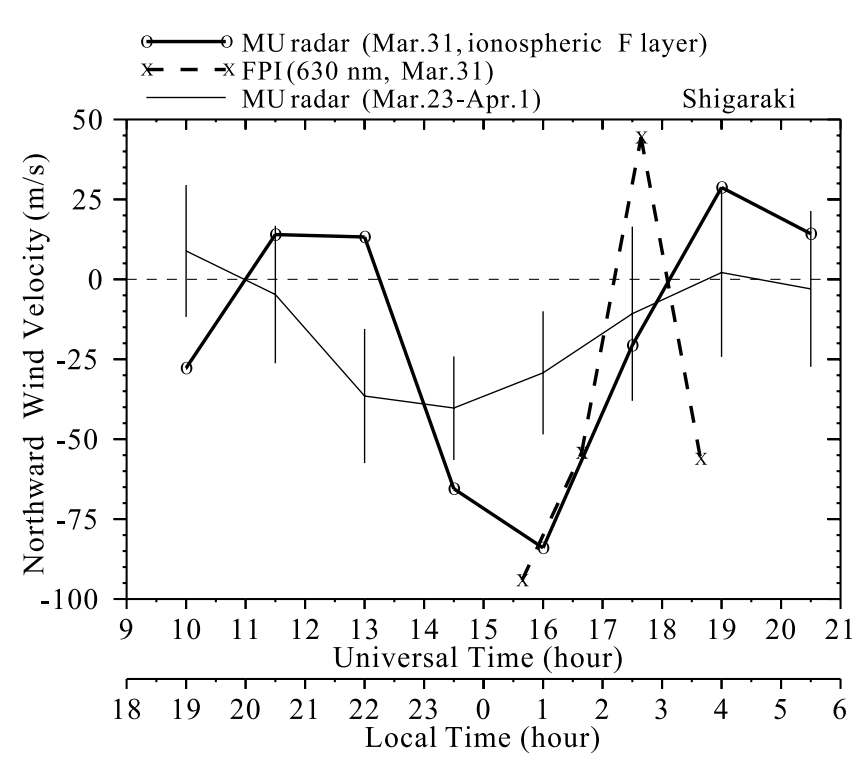

Figure 9. Northward wind velocities in the thermosphere measured by the MU radar and by the Fabry-Perot interferometer (FPI) at Shigaraki. The MU radar winds are estimated from $F$-layer ion drift measurements. The thin solid curve is averages of MU radar winds measured for 23 March to 1 April 2001 (except for 31 March), where the vertical bars indicate standard deviations. The thick solid curve with circles is the MU radar wind of 31 March 2001. The thick dashed curve with Xs is the FPI wind measured through the Doppler shift of $630-\mathrm{nm}$ airglow emission (emission altitude: $\sim 200-300 \mathrm{~km}$ ). 


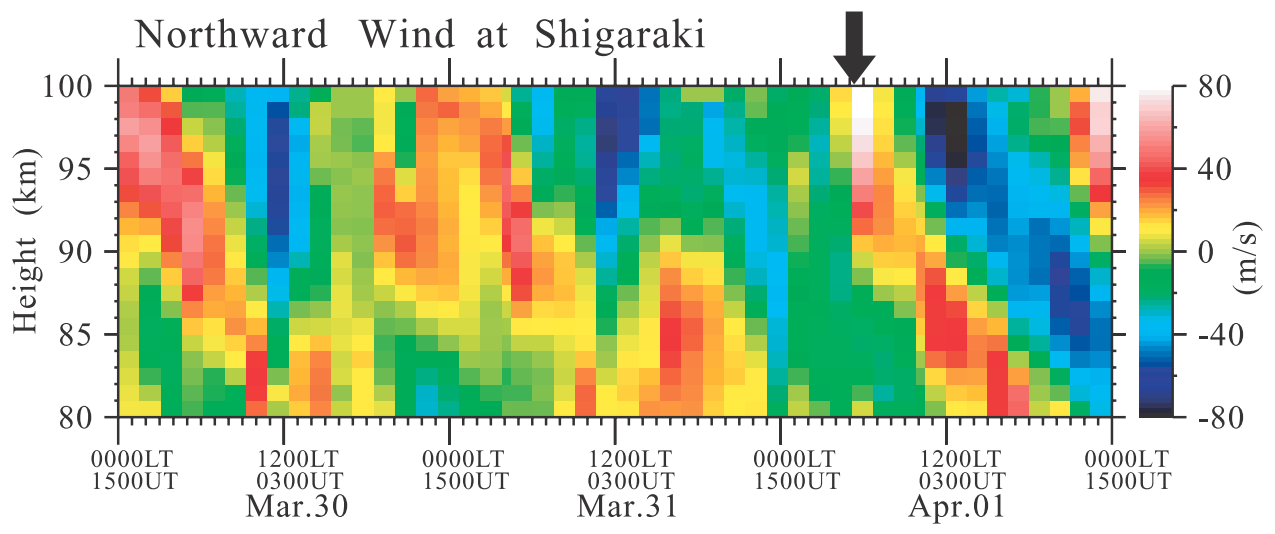

Figure 10. Northward wind velocities in the mesopause region measured by the MU radar through meteor echoes at Shigaraki on 30 March to 1 April 2001. The arrow indicates the time when intense northward wind was observed at high altitudes associated with the LSTID passage.

This increase in wind was largest compared with other days of the MTEC-S campaign, the average of which is shown by the thin solid curve, with vertical bars indicating standard deviations.

\section{High-Latitude Disturbances}

[26] To show geomagnetic activity during the LSTID event, we plotted the H-component magnetic field variations of 31 March 2001 in Figure 12. The data $\left(210^{\circ}\right.$ magnetic meridian chain data, see Yumoto et al. [1996] for details) were obtained mostly in the Japanese meridian of 0200-0300 magnetic local times (MLTs) in Siberia (auroral zone, TIX, and CHD), southern Siberia (ZYK and MGD), Japan (MSR, RIK, and KAG), and Australia (BSV). Low-latitude data in the morning sector at Hawaii (EWA, 6.9 MLT) are also shown.

[27] The LSTID passage over Japan was 1700-1900 UT. At 1540-1700 UT, an intense substorm was observed with a negative $\mathrm{H}$ bay at TIX, CHD, ZTK, and MGD. Positive $\mathrm{H}$ excursions, which are usually seen in the low-latitude magnetograms associated with substorms, were observed at the low-latitude stations (MSR, RIK, KAG, EWA, and $\mathrm{BSV}$ ) at this time. Note that the negative $\mathrm{H}$ bay was also observed at MGD $\left(53.8^{\circ}\right.$ MLAT), indicating that the auroral electrojet current came down to lower latitudes during the main phase of the large magnetic storm.

[28] In order to see the energy input in the auroral zone, we show the Northern Hemisphere auroral Joule heating rate, cross polar-cap potential, and AU/AL indices calculated by the AMIE technique [Richmond and Kamide, 1988] in Figure 13. The AMIE procedure calculates these parameters from ground magnetometer data using the inversion technique by considering ionospheric conductivity. The highlatitude magnetometer data shown in Figure 12 are also used in this empirical model.

[29] The polar-cap potential and auroral Joule heating generally show high values of more than $100 \mathrm{kV}$ and $500 \mathrm{GW}$ during the plotted interval, because of the main phase of the large magnetic storm. The AU/AL indices in the top panel show an intense substorm that started at 1540 UT. This substorm causes the enhancements of auroral Joule heating from $500 \mathrm{GW}$ to $1000 \mathrm{GW}$ and the polar-cap potential drop from $120 \mathrm{kV}$ to $150 \mathrm{kV}$, with even higher values around $1820 \mathrm{UT}$.

\section{Discussion}

\subsection{Wind Measurement}

[30] Figure 14 is a summary plot of the observed features of the LSTID of 31 March 2001. The LSTID at 17001900 UT (0200-0400 LT) observed in Japan was characterized by enhancements of $630-\mathrm{nm}$ airglow and $f_{o F}$,

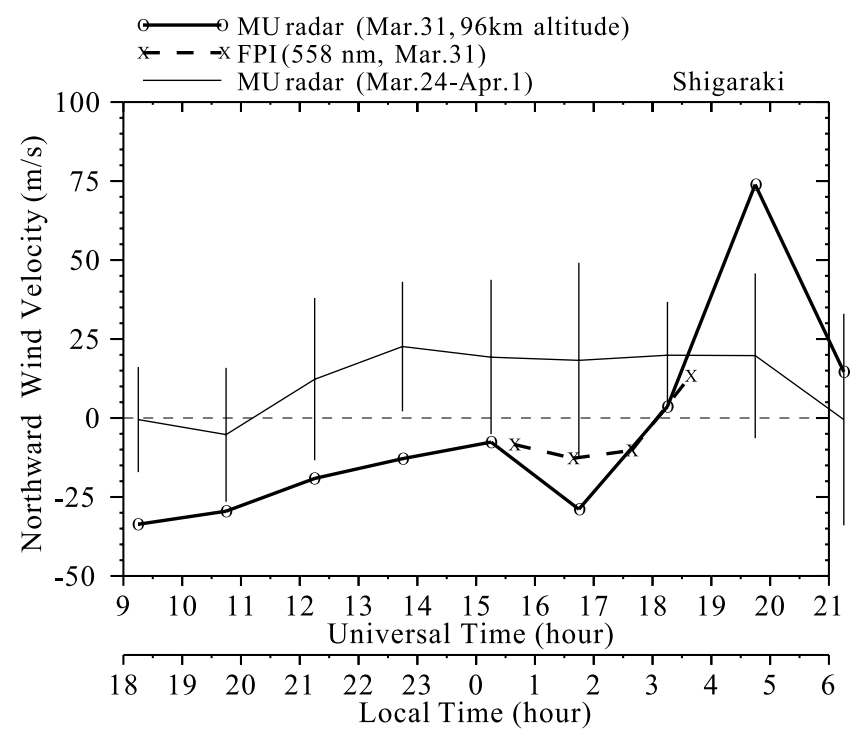

Figure 11. Northward wind velocities in the mesopause region measured by the MU radar and by the Fabry-Perot interferometer (FPI) at Shigaraki. The MU radar wind at an altitude of $96 \mathrm{~km}$ is measured through meteor echoes. The thin solid curve is averages of MU radar winds for 24 March to 1 April 2001 (except for 31 March), where the vertical bars indicate standard deviations. The thick solid curve with circles is the MU radar wind of 31 March 2001. The thick dashed curve with Xs is the FPI wind measured through the Doppler shift of 558-nm airglow emission (emission altitude: $\sim 90-100 \mathrm{~km}$ ). 
Ordinary Magnetograms (H Component) station March 31, 2001

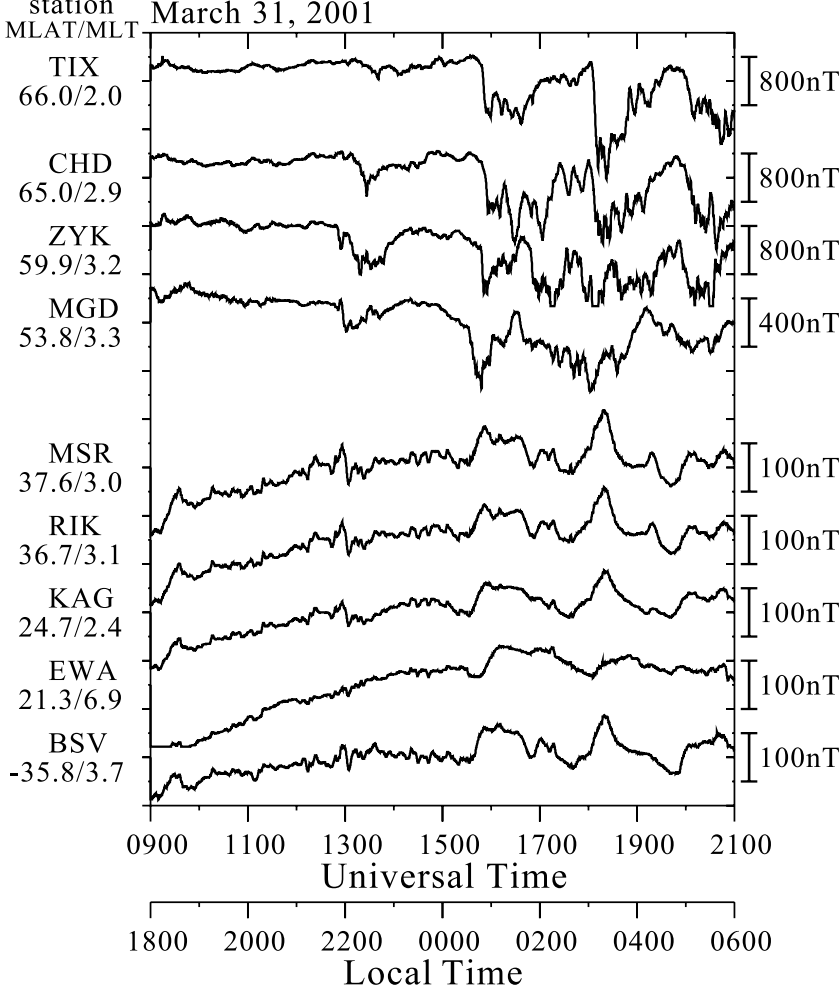

Figure 12. H-component magnetic field variations (positive: northward) observed at high-latitude and low-latitude stations along the Japanese meridian for 0900-2100 UT on 31 March 2001. Station names, magnetic latitudes (MLAT), and magnetic local times (MLT) at 1800 UT are shown at the left side of the panels, where TIX, CHD, ZYK, MGD, MSR, RIK, KAG, EWA, and BSV are Tixie, Chokurdakh, Zyryanka, Magadan, Moshiri, Rikubetsu, Kagoshima, Ewa Beach, and Birdsville, respectively.

GPS-TEC variations, and a decrease in F-layer virtual height. These characteristics are similar to those seen in the LSTID event of 15 September 1999, reported by Shiokawa et al. [2002]. We also measured $F$-layer electron density profiles observed by the MU radar for the present event. The profiles show a sudden descent of the $F$ layer during the passage of the LSTID. During the descent of the $F$ layer, poleward wind enhancement (from $-94 \mathrm{~m} / \mathrm{s}$ to $+44 \mathrm{~m} / \mathrm{s}$ ) was observed in the thermosphere by the MU radar and the FPI. To our knowledge, they are the first combined measurements of LSTID images and neutral wind at midlatitudes.

[31] As illustrated in Figure 9 of Shiokawa et al. [2002], the poleward wind pushes the ionosphere down along the field line at midlatitudes. This $F$-layer descent causes airglow enhancement by supplying the high-density plasma at the $F$-layer peak $(\sim 400 \mathrm{~km})$ to the airglow emission layer at $\sim 250 \mathrm{~km}$. The $F$-layer peak electron density ( $f_{O} F 2$ ) temporally increases to keep the pressure balance along the field line ("compression" of the $F$ layer). Such enhancement of the $F$-layer peak was also detected by the MU radar (Figure 8, around 1645 UT). The F-layer descent causes a pressure decrease at the high-altitude ionosphere, which results in the observed slight TEC enhancement by the supply of electrons from the higher altitudes and from the other hemisphere along the field line. The $F$-layer peak electron density and TEC are then significantly decreased because of the severe recombination at lower altitudes.

[32] We detected the poleward wind enhancement not only in the thermosphere but also in the mesopause region, where it was delayed $\sim 2 \mathrm{~h}$ from that in the thermosphere. Such a delay at lower altitudes was predicted by Richmond [1978], who used numerical simulation of large-scale gravity waves in the thermosphere. He showed that the phase front of the equatorward moving waves at a $100-\mathrm{km}$ altitude was delayed $\sim 20^{\circ}$ in latitude from that at a $250-\mathrm{km}$ altitude at midlatitudes (see Figure 7 of Richmond [1978]). This delay was because an upward propagating gravity wave (generated at an auroral-zone heat source at altitudes of $100-160 \mathrm{~km}$ in his simulation) has a downward propagating phase front [Hines, 1960]. The phase delay of $\sim 20^{\circ}$ in latitude in his simulation causes a time delay of $\sim 1 \mathrm{~h}$ at altitudes between 401 and $209 \mathrm{~km}$ at $46^{\circ} \mathrm{N}$. For the present event, the phase delay from a $250-\mathrm{km}$ altitude to a $96-\mathrm{km}$ altitude was $\sim 2 \mathrm{~h}$ at $35^{\circ} \mathrm{N}$ (Shigaraki). The amplitude of poleward wind enhancement at 209-km altitude is $1 / 6$ of that at $401 \mathrm{~km}$ in the work of Richmond [1978]. For the present event, the wind enhancement at a $250-\mathrm{km}$ altitude was $138 \mathrm{~m} / \mathrm{s}$ (FPI measurement at $630 \mathrm{~nm}$ ). The enhancement at the mesospheric altitudes would be well less than

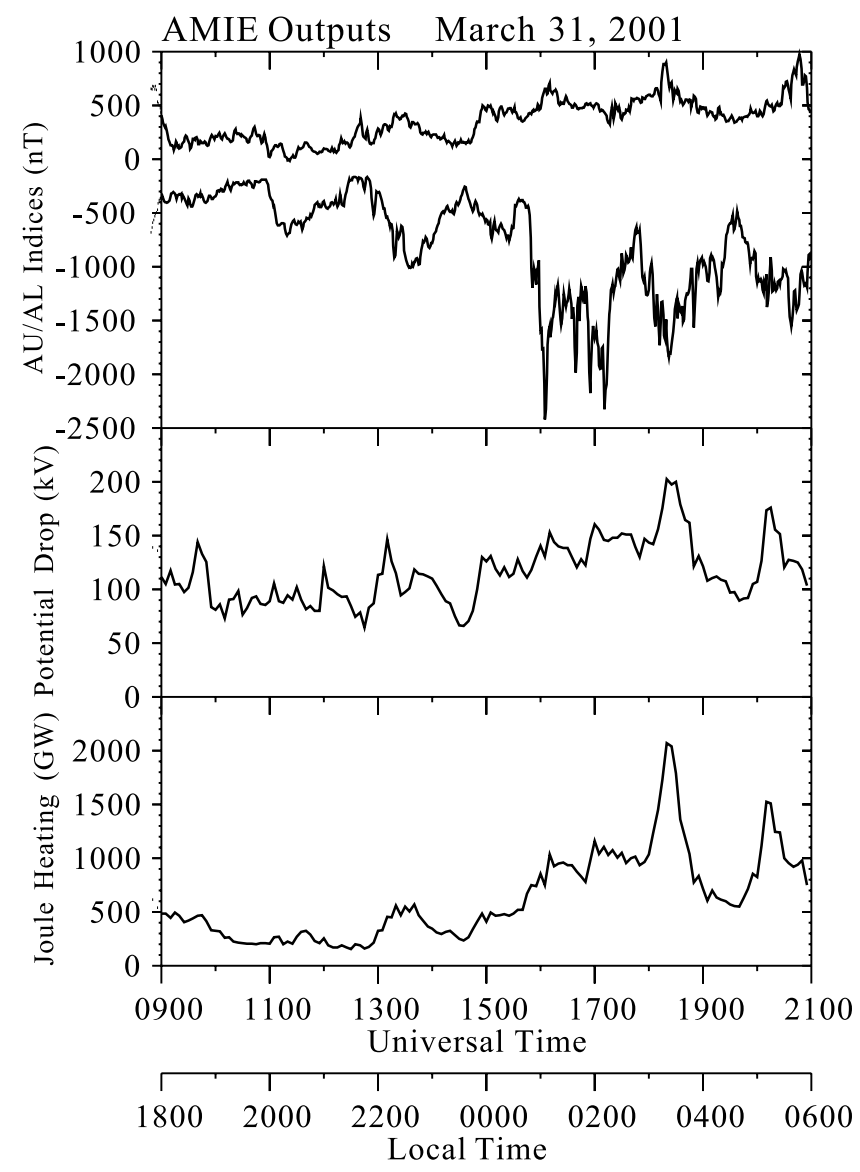

Figure 13. Northern Hemisphere Joule heating rate, cross polar cap potential, and AU/AL indices calculated by the assimilative mapping of ionospheric electrodynamics (AMIE) technique for 0900-2100 UT of 31 March 2001. 


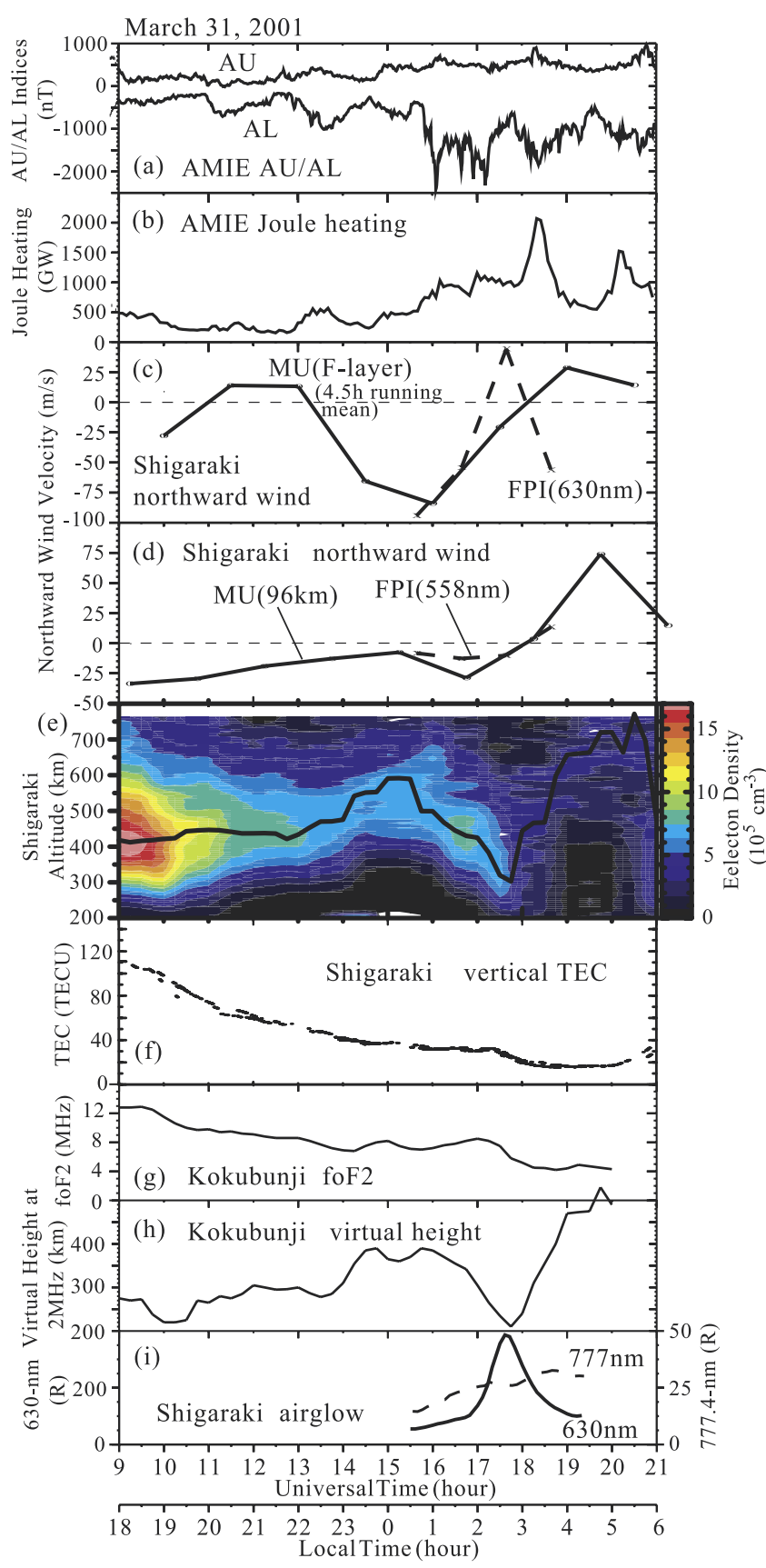

Figure 14. From top to bottom, (a) AU/AL indices and (b) Northern Hemisphere Joule heating calculated by the assimilative mapping of ionospheric electrodynamics (AMIE) technique, northward neutral wind (c) at $F$-layer height and (d) in the mesopause region measured by the MU radar and a Fabry-Perot interferometer at Shigaraki, (e) height profile of the $F$-region electron density (solid curve: peak height) measured by the MU radar at Shigaraki, (f) vertical TEC values obtained by GEONET at Shigaraki, (g) foF 2 and (h) virtual height at $2 \mathrm{MHz}$ measured by an ionosonde at Kokubunji, and (i) airglow intensities at $630 \mathrm{~nm}$ and $777 \mathrm{~nm}$ measured at Shigaraki, for 0900 2100 UT of 31 March 2001. $\sim 80 \mathrm{~m} / \mathrm{s}$ considering the overlap of tidal variation in the meteor radar data.

[33] Using data from the MU radar and the ionosonde network, Reddy et al. [1990] reported similar variations of the midlatitude ionosphere during the magnetic storm of 20-21 January 1989. They showed a rapid increase in the $F$-layer height from $1400 \mathrm{UT}(370 \mathrm{~km})$ to $1600 \mathrm{UT}$ $(600 \mathrm{~km})$ and a sudden decrease in the height from 1600 UT $(600 \mathrm{~km})$ to 1730 UT (less than $350 \mathrm{~km}$ ) observed by the MU radar (their Figure 4). These features are quite similar to those of the present event. Using the density variations obtained from the MU radar, Reddy et al. [1990] estimated the meridional wind velocity (by assuming that the east-west electric field $=0 \mathrm{mV} / \mathrm{m}$ ) and the east-west electric field (by assuming that the meridional wind $=0 \mathrm{~m} / \mathrm{s}$ ). In the present paper, we show the meridional wind velocities from the direct measurements made by the MU radar and the FPI. Their result (Figure 9 of Reddy et al. [1990]) shows variation of meridional wind quite similar to our Figure 9, but the amplitude was much larger $( \pm 200 \mathrm{~m} / \mathrm{s})$. For the present event, we can safely conclude that the LSTID was not caused by the global east-west electric field imposed on the ionosphere from magnetospheric disturbances, because of the clear southward propagation of the observed ionospheric disturbances.

[34] The slight decrease in the 777-nm airglow at the passage of the LSTID (Figure 4) can also be explained by the $F$-layer decrease, because the 777-nm emission intensity is proportional to the square of the $F$-layer peak electron density [e.g., Sahai et al., 1981]. However, the 777-nm intensity recovers and further increases after the LSTID passage, though the $F$-layer density does not recover in Figure 8. At midlatitudes, the 777-nm intensity is relatively weak compared with that at equatorial latitudes. Because the $\mathrm{OH}(9-4) P_{2}(2)$ line (wavelength: $778.2 \mathrm{~nm}$ ) falls into the pass band of our 777.4-nm filter, the observed 777-nm intensity is probably highly contaminated by the $\mathrm{OH}$ airglow emission from the mesopause region. The recovery of the 777-nm intensity after the LSTID passage may be because of this contamination.

[35] The 558-nm airglow intensity was unusually intense on this night, particularly in the southern part of Japan (maximum $870 \mathrm{R}$ at Sata). This intense 558-nm airglow cannot be explained by the $F$-region contribution of the $558-\mathrm{nm}$ airglow in the equatorial anomaly region because the $F$-region contribution of 558-nm airglow is usually 20 $30 \%$ of the $630-\mathrm{nm}$ airglow. There seems to be some unknown mechanism that causes further excitation of $\mathrm{O}\left({ }^{1} \mathrm{~S}\right)$ at midlatitudes during this storm.

[36] It is interesting to note that the amplitude of the TEC variations in Figure 5 becomes larger at lower latitudes. This may correspond to the latitudinal gradient of background TEC because if the TEC variation is caused by meridional wind variations, it would become larger under the large-background TEC. However, there is no discernible TEC enhancement in the northern part of Japan before 1705 UT. In addition, the 630-nm airglow enhancement is larger at lower latitudes (Sata), as shown in Figure 4. The observed increase of the amplitudes in TEC and airglow at lower latitudes may suggest enhancement of the meridional wind variation, which may correspond to the nonlinear 
development of a large-amplitude traveling atmospheric wave as it propagates from higher to lower latitudes.

\subsection{Source in the Auroral Zone}

[37] The atmospheric wave that caused the observed LSTID was probably generated by the auroral-zone energy input. From the UV auroral images obtained by the POLAR satellite (not shown), the auroral oval expanded down to the geographic latitude of $\sim 60^{\circ}\left(\sim 50^{\circ}\right.$ MLAT) in the Japanese meridian at 1600 UT. This was confirmed by the fact that an intense auroral electrojet was observed at MGD $\left(59.9^{\circ}\right.$ GLAT, $53.8^{\circ}$ MLAT), as shown in Figure 12. If we take the equatorward velocity of the LSTID to be $600 \mathrm{~m} / \mathrm{s}$, it takes $\sim 1.3$ hours to propagate from $60^{\circ}$ GLAT to $35^{\circ}$ GLAT (Shigaraki). Since the LSTID was observed at Shigaraki at 1730-1800 UT, it was probably generated in the auroral oval around 1600-1630 UT, when an intense storm-time substorm took place.

[38] LSTID simulations with auroral energy input generally predict "equatorward" wind enhancement during the auroral energy input because of the expansion of the heated atmosphere. Some have predicted poleward wind enhancement at midlatitudes after passage of the initial equatorward wind, due to rarefaction [e.g., Richmond, 1978; Millward et al., 1993]. In the thermospheric wind data in Figure 14c, the equatorward wind enhancement was seen at 1300-1600 UT, before the poleward wind enhancement at 1700-1800 UT. However, it is impossible to connect this equatorward wind at 1300-1600 UT to the intense substorm starting at 1540 UT. The Joule heating estimated by AMIE shows a small enhancement at 1300-1400 UT in the auroral zone (Figure 14b), which may correspond to the equatorward wind enhancement observed in Japan at 1300-1600 UT (Figure 14c). However, it is not likely that this small auroral-zone heating at 1300-1400 UT caused the intense poleward wind enhancement observed in Japan at 17001800 UT through the rarefaction.

[39] The other mechanism that can cause "poleward" wind during auroral energy input is the Lorentz force in the auroral zone. As discussed by Hunsucker [1982], the Lorentz force $(\mathbf{J} \times \mathbf{B})$, where $\mathbf{J}$ is the auroral current density and $\mathbf{B}$ is the magnetic field intensity, can be transferred to the neutral gas via collisions. This force can be imposed in the auroral zone to cause LSTIDs, which propagate equatorward as traveling atmospheric waves. For the present event, however, the auroral-zone current $\mathbf{J}$ associated with the storm-time substorm around 1600-1630 UT is clearly westward, as shown by negative-bay variations in the H-component (northward component) magnetic field in Figure 12. The westward electrojet current causes an "equatorward" $\mathbf{J} \times \mathbf{B}$ force in the northern hemisphere.

[40] From the timing and the propagation velocity, it is quite conceivable that the LSTID observed in Japan at 1700-1800 UT is related to the intense storm-time substorm at 1600-1630 UT. However, neither Joule heating nor the Lorentz force explains the generation of the observed LSTID (poleward wind enhancement) in the auroral zone. There may be some wave-wave coupling and modulation of gravity waves due to complicated spatial and temporal structures of auroral energy input, as discussed by Rice et al. [1988] and Jing and Hunsucker [1993]. To investigate this missing link between the middle and high latitudes, we need to compare our observations with global circulation models of the upper atmosphere using observed parameters of auroral energy input, as was done by Emery et al. [1996, 1999], Buonsanto et al. [1997], and Lu et al. [2001].

\section{Conclusions}

[41] We have reported a prominent LSTID event with neutral wind data in the midlatitude thermosphere and the mesopause region during the magnetic storm of 31 March 2001. The observed features of the LSTID and related phenomena are summarized as follows.

[42] 1. Drastic airglow enhancements of $100 \rightarrow 400 \mathrm{R}$ (Shigaraki) and $200 \rightarrow 750 \mathrm{R}$ (Sata) propagating equatorward $(\sim 640 \mathrm{~m} / \mathrm{s})$ were observed by all-sky imagers at $1700-$ 1900 UT (0200-0400 LT). The 558-nm airglow increased in association with the LSTID, while the 777-nm airglow slightly decreased. Intense 558-nm airglow (870 R) was observed in the southern part of Japan.

[43] 2. The GPS-TEC maps over Japan showed a slight enhancement and subsequent decrease in TEC with a meridional scale size of $\sim 600-800 \mathrm{~km}$, propagating equatorward with a velocity of $\sim 370-560 \mathrm{~m} / \mathrm{s}$ at $1710_{-}$ 1740 UT. The TEC variations were $\sim 1-2 \times 10^{16} \mathrm{~m}^{-2}$ ( $\sim 2-6 \%$ of background TEC).

[44] 3. The $F$-layer virtual height at $2 \mathrm{MHz}$ decreased from $\sim 400 \mathrm{~km}$ to $\sim 200 \mathrm{~km}$ at $1700-1900$ UT at three ionosonde stations in Japan. The minimum of the virtual height moved equatorward with a velocity of $\sim 580 \mathrm{~m} / \mathrm{s}$. The foF 2 values increased just before the virtual height minimum.

[45] 4. The descent of the $F$ layer associated with the LSTID was clearly observed at 1530-1745 UT (00300245 LT) by the MU radar at Shigaraki. Before the LSTID, the $F$-layer height rapidly increased at $1300-1530$ UT.

[46] 5. The thermospheric neutral wind was estimated from the ion drift measurement by the MU radar and was measured by the FPI through the 630-nm airglow. The data indicated a sudden enhancement of the poleward neutral wind of $\sim 140 \mathrm{~m} / \mathrm{s}$ at $1700-1800$ UT during the LSTID passage. The meridional wind showed large-amplitude wavelike variations throughout the night (northward at 1200-1300 UT, highly southward at 1400-1600 UT, and northward at 1900-2100 UT).

[47] 6. The mesospheric neutral wind (around an altitude of $\sim 96 \mathrm{~km}$ ) was measured by the MU radar through meteor echoes and by the FPI through the 558-nm airglow. The data also showed sudden enhancement of the poleward wind at 2000 UT, $\sim 2$ hours after the poleward wind enhancement in the thermosphere.

[48] 7. Ground magnetic field data and AMIE outputs showed that an intense substorm took place at 15401700 UT, which corresponds to the onset time of the LSTID estimated by backtracing the LSTID propagation observed in Japan to the auroral zone.

[49] These observed features of the LSTID are similar to those reported by Reddy et al. [1990] and Shiokawa et al. [2002]. In addition, this work reports the first simultaneous measurement of the neutral wind and LSTID images at midlatitudes. The 630-nm airglow enhancement, 777-nm airglow decrease, $F$-layer descent, TEC variations, and 
temporal increase of $f_{o F} 2$ are probably caused by the observed poleward wind enhancement in the thermosphere, as suggested by Shiokawa et al. [2002] (their Figure 9). The observed time delay of the mesospheric wind enhancement is consistent with the vertical phase front distribution of the upward propagating gravity wave, as predicted by Richmond [1978]. However, simple atmospheric heating and/or the Lorentz force in the auroral zone do not explain the observed poleward wind enhancement at midlatitudes. A comparison with global thermospheric models will be needed for further investigation.

[50] Acknowledgments. We thank Y. Katoh, M. Satoh, T. Katoh, and K. Hidaka of the Solar-Terrestrial Environment Laboratory, Nagoya University, for their kind support of the development and operation of the all-sky imagers and the Fabry-Perot interferometer. The observation at Shigaraki was carried out in collaboration with the Radio Science Center for Space and Atmosphere, Kyoto University. The MU radar at Shigaraki belongs to and is operated by the Radio Science Center for Space and Atmosphere, Kyoto University. The magnetic field data were provided by the $210^{\circ}$ magnetic meridian magnetic observation project. The multipoint GPS data were supplied by the Geographical Survey Institute, Japan. The ionograms were supplied through WDC-C2 for ionosphere, Communications Research Laboratory, Tokyo. The POLAR UVI images mentioned in the text were provided by G. Parks at the University of Washington and the CDAWeb. N. Balan is supported by PPARC (UK) grant PPA/G/S/1999/ 00705. This work was supported by a Grant-in-Aid for Scientific Research of the Ministry of Education, Culture, Sports, Science and Technology of Japan (11440145, 13573006, and 13136201).

[51] Lou-Chuang Lee thanks Barbara A. Emery and Robert D. Hunsucker for their assistance in evaluating this paper.

\section{References}

Balthazor, R. L., and R. J. Moffett, Morphology of large-scale traveling atmospheric disturbances in the polar thermosphere, J. Geophys. Res., 104, 15-24, 1999.

Blanc, M., and A. D. Richmond, The ionospheric disturbance dynamo, J. Geophys. Res., 85, 1669-1686, 1980.

Buonsanto, M. J., M. Codrescu, B. A. Emery, C. G. Fesen, T. J. FullerRowell, D. J. Melendez-Alvira, and D. P. Sipler, Comparison of models and measurements at Millstone Hill during the January 24-26, 1993, minor storm interval, J. Geophys. Res., 102, 7267-7277, 1997.

Emery, B. A., et al., Assimilative mapping of ionospheric electrodynamics in the thermosphere-ionosphere general circulation model comparisons with global ionospheric and thermospheric observations during the GEM/ SUNDIAL period of March 28-29, 1992, J. Geophys. Res., 101, 26,681-26,696, 1996.

Emery, B. A., C. Lathuillere, P. G. Richards, R. G. Roble, M. J. Buonsanto, D. J. Knipp, P. Wilkinson, D. P. Sipler, and R. Niciejewski, Time dependent thermospheric neutral response to the 2-11 November 1993 storm period, J. Atmos. Sol. Terr. Phys., 61, 329-350, 1999.

Fejer, B. G., J. T. Emmert, and D. P. Sipler, Climatology and storm time dependence of nighttime thermospheric neutral winds over Millstone Hill, J. Geophys. Res., 107(A5), 1052, doi:10.1029/2001JA000300, 2002.

Francis, S. H., Global propagation of atmospheric gravity waves: A review, J. Atmos. Terr. Phys., 37, 1011-1054, 1975.

Fujiwara, H., S. Maeda, H. Fukunishi, T. J. Fuller-Rowell, and D. S. Evans, Global variations of thermospheric winds and temperatures caused by substorm energy injection, J. Geophys. Res., 101, 225-239, 1996.

Fuller-Rowell, T. J., M. V. Codrescu, R. J. Moffett, and S. Quegan, Response of the thermosphere and ionosphere to geomagnetic storms, J. Geophys. Res., 99, 3893-3914, 1994.

Hajkowicz, L. A., A global study of large scale travelling ionospheric disturbances (TIDs) following a step-like onset of auroral substorms in both hemispheres, Planet. Space Sci., 38, 913-923, 1990.

Hajkowicz, L. A., and R. D. Hunsucker, A simultaneous observation of large-scale periodic TIDs in both hemispheres following an onset of auroral disturbances, Planet. Space Sci., 35, 785-791, 1987.

Hines, C. O., Internal atmospheric gravity waves at ionospheric heights, Can. J. Phys., 38, 1441-1481, 1960.

Ho, C. M., A. J. Mannucci, U. J. Lindqwister, X. Pi, and B. T. Tsurutani, Global ionosphere perturbations monitored by the worldwide GPS network, Geophys. Res. Lett., 23, 3219-3222, 1996.

Ho, C. M., A. J. Mannucci, L. Sparks, X. Pi, U. L. Lindqwister, B. D. Wilson, B. A. Iijima, and M. J. Reyes, Ionospheric total electron con- tent perturbations monitored by the GPS global network during two northern hemisphere winter storms, J. Geophys. Res., 103, 26,40926,420, 1998

Hocke, K., and K. Schlegel, A review of atmospheric gravity waves and traveling ionospheric disturbances: 1982-1995, Ann. Geophys., 14, 917-940, 1996.

Hooke, W. H., Ionospheric irregularities produced by internal atmospheric gravity waves, J. Atmos. Terr. Phys., 30, 795-823, 1968

Hunsucker, R. D., Atmospheric gravity waves generated in the high-latitude ionosphere: A review, Rev. Geophys., 20, 293-315, 1982.

Jing, N., and R. D. Hunsucker, A theoretical investigation of sources of large and medium scale atmospheric gravity waves in the auroral oval, J. Atmos. Terr. Phys., 55, 1667-1679, 1993.

Kamide, Y., A. D. Richmond, and S. Matsushita, Estimation of ionospheric electric fields, ionospheric currents, and field-aligned currents from ground magnetic records, J. Geophys. Res., 86, 801-813, 1981.

Kawamura, S., Y. Otsuka, S.-R. Zhang, S. Fukao, and W. L. Oliver, A climatology of middle and upper atmosphere radar observations of thermospheric winds, J. Geophys. Res., 105, 12,777-12,788, 2000.

Lee, C.-C., J.-Y. Liu, B. W. Reinisch, T.-P. Lee, and L. Liu, The propagation of traveling atmospheric disturbances observed during the April 6-7, 2000 ionospheric storm, Geophys. Res. Lett., 29(5), 1068, doi:10.1029/ 2001GL013516, 2002.

Lu, G., A. D. Richmond, R. G. Roble, and B. A. Emery, Coexistence of ionospheric positive and negative storm phases under northern winter conditions: A case study, J. Geophys. Res., 106, 24,49324,504, 2001 .

Millward, G. H., R. J. Moffett, S. Quegan, and T. J. Fuller-Rowell, Effects of an atmospheric gravity wave on the midlatitude ionospheric $F$ layer, J. Geophys. Res., 98, 19,173-19,179, 1993.

Nakamura, T., T. Tsuda, M. Tsutsumi, K. Kita, T. Uehara, S. Kato, and $\mathrm{S}$. Fukao, Meteor wind observations with the MU radar, Radio Sci., 26, $857-869,1991$.

Ogawa, T., and H. Kumagai, Deep depletions of total electron content associated with severe mid-latitude gigahertz scintillations during geomagnetic storms, J. Geophys. Res., 90, 6652-6656, 1985.

Oliver, W. L., Y. Otsuka, and S. Fukao, MST radar measurement of ionospheric $F$ region winds: The "layer wind" technique, Radio Sci., 33, 941-948, 1998.

Otsuka, Y., T. Ogawa, A. Saito, T. Tsugawa, S. Fukao, and S. Miyazaki, A new technique for mapping of total electron content using GPS network in Japan, Earth Planet. Space, 54, 63-70, 2002.

Oyama, S., M. Ishii, Y. Murayama, H. Sinagawa, S. C. Buchert, R. Fujii, and W. Kofman, Generation of atmospheric gravity waves associated with auroral activity in the polar $F$ region, J. Geophys. Res., 106, $18,543-18,554,2001$

Pi, X., M. Mendillo, W. J. Hughes, M. J. Buonsanto, D. P. Sipler, J. Kelly, Q. Zhou, G. Lu, and T. J. Hughes, Dynamical effects of geomagnetic storms and substorms in the middle-latitude ionosphere: An observational campaign, J. Geophys. Res., 105, 7403-7417, 2000.

Reddy, C. A., S. Fukao, T. Takami, M. Yamamoto, T. Tsuda, T. Nakamura, and S. Kato, A MU radar-based study of mid-latitude $F$ region response to a geomagnetic disturbance, J. Geophys. Res., 95, 21,077-21,094, 1990.

Rice, D. D., R. D. Hunsucker, L. J. Lanzerotti, G. Crowley, P. J. S. Williams, J. D. Craven, and L. Frank, An observation of atmospheric gravity wave cause and effect during the October 1985 WAGS campaign, Radio Sci., 23, 919-930, 1988.

Richmond, A. D., Gravity wave generation, propagation, and dissipation in the thermosphere, J. Geophys. Res., 83, 4131-4145, 1978.

Richmond, A. D., and Y. Kamide, Mapping electrodynamic features of the high-latitude ionosphere from localized observations: Technique, J. Geophys. Res., 93, 5741-5759, 1988.

Sahai, Y., J. A. Bittencourt, N. R. Teixeira, and H. Takahashi, Simultaneous observations of OI 7774-A and OI 6300-A emissions and correlative study with ionospheric parameters, J. Geophys. Res., 86, 3657-3660, 1981 .

Saito, A., S. Fukao, and S. Miyazaki, High resolution mapping of TEC perturbations with the GSI GPS network over Japan, Geophys. Res. Lett., 25, 3079-3082, 1998

Shiokawa, K., Y. Katoh, M. Satoh, M. K. Ejiri, T. Ogawa, T. Nakamura, T. Tsuda, and R. H. Wiens, Development of optical mesosphere thermosphere imagers (OMTI), Earth Planet. Space, 51, 887-896, 1999.

Shiokawa, K., Y. Katoh, M. Satoh, M. K. Ejiri, and T. Ogawa, Integratingsphere calibration of all-sky cameras for nightglow measurements, $A d v$. Space Sci., 26, 1025-1028, 2000.

Shiokawa, K., Y. Otsuka, T. Ogawa, N. Balan, K. Igarashi, A. J. Ridley, D. J. Knipp, A. Saito, and K. Yumoto, A large-scale traveling ionospheric disturbance during the magnetic storm of September 15, 1999, J. Geophys. Res., 107(A6), 1088, doi:10.1029/2001JA000245, 2002. 
Shiokawa, K., T. Kadota, Y. Otsuka, T. Ogawa, T. Nakamura, and S. Fukao, A two-channel Fabry-Perot interferometer with thermoelectric-cooled CCD detectors for neutral wind measurement in the upper atmosphere, Earth Planet. Space, 55, 271-275, 2003.

Tanaka, T., An important role of electric field reversals for the initiation of Gigahertz scintillations at midlatitude during geomagnetic storms, J. Geomagn. Geoelectr, 39, 659-676, 1987.

Yumoto, K., et al., The STEP 210 (deg) magnetic meridian network project, J. Geomagn. Geoelectr., 48, 1297-1309, 1996.

N. Balan, Department of Automatic Control and Systems Engineering, University of Sheffield, Amy Johnson Building, Mappin Street, Sheffield, S1 3JD, UK. (b.nanan@sheffield.ac.uk)

S. Fukao, S. Kawamura, T. Nakamura, T. Tsuda, and M. Yamamoto, Radio Science Center for Space and Atmosphere, Kyoto University, Gokanosho, Uji, Kyoto 611-0011, Japan. (fukao@kurasc.kyoto-u.ac.jp; kawamura@kurasc.kyoto-u.ac.jp; nakamura@kurasc.kyoto-u.ac.jp; tsuda@ kurasc.kyoto-u.ac.jp; yamamoto@kurasc.kyoto-u.ac.jp)

K. Igarashi, Communications Research Laboratory, 4-2-1, Nukui-Kita, Koganei, Tokyo 184-8795, Japan. (igarashi@crl.go.jp)

G. Lu, High Altitude Observatory, National Center for Atmospheric Research, 3450 Mitchell Lane, Boulder, CO 30301, USA. (ganglu@hao. ucar.edu)

T. Ogawa, Y. Otsuka, and K. Shiokawa, Solar-Terrestrial Environment Laboratory, Nagoya University, Toyokawa 442-8507, Japan. (ogawa@ stelab.nagoya-u.ac.jp; otsuka@stelab.nagoya-u.ac.jp; shiokawa@stelab. nagoya-u.ac.jp)

A. Saito, Graduate School of Science, Kyoto University, KitashirakawaOiwakecho, Sakyo-ku, Kyoto 606-8502, Japan. (saitoua@kugi.kyoto-u. ac.jp)

K. Yumoto, Space Environment Research Center, Kyushu University 33 6-10-1, Hakozaki, Higashi-ku, Fukuoka 812-8581, Japan. (yumoto@geo. kyushu-u.ac.jp) 